\title{
Personal and spousal decision making on the funding of medical care not covered by healthcare insurance
}

\author{
Maya Kagan \\ Department of Health Management, Ariel University, I srael
}

Correspondence: Maya Kagan. Address: Department of Health Management, Ariel University, Israel. E-mail: mayakagan1@gmail.com

Received: December 26, 2012

Accepted: January 27, 2013

Online Published: February 16, 2013

DOI : $10.5430 /$ jha.v2n3p8

URL: http://dx.doi.org/10.5430/jha.v2n3p8

\section{Abstract}

The purpose of this study was to investigate personal and spousal decisions to seek funding for spousal medical care, when such treatments are not covered by the National Package of Healthcare Services or by other types of healthcare insurance. Research data were collected in Israel during 2008-2010 by means of structured questionnaires. The questionnaires were administered to a nonrandom sample of 160 patients with a health condition requiring private funding of treatment. The study clearly reveals that the decision to forego fundraising results not only from financial considerations. Patients' illness-related factors and available personal, spousal, and social resources are significant as well.

\section{Key words}

Healthcare insurance, Decision making, Funding of medical care, Patients' personal, Spousal, Social resources

\section{I ntroduction}

The US Federal Health Care Reform bill obliges all US citizens to purchase healthcare insurance. Nationwide coverage and prohibiting discrimination against insurance purchasers are an important social step, contributing to the pro-social character of the American healthcare system, in a manner resembling that of certain western countries (such as Israel).

Israel's healthcare reform ${ }^{[1]}$ has made all Israeli citizens eligible for an elementary package of healthcare services. This package consists of basic medical services and preparations subsidized by the state. In addition, in their competition for customers, Israeli Health Funds (HF) may choose to subsidize other services and preparations. Moreover, in order to receive wider and better services, customers may purchase additional healthcare coverage from their HFs or from private insurance companies. Although the Israeli healthcare system seemingly provides for all its customers' needs, this premise is completely erroneous. Many medical technologies and services are not included in the National Package of Healthcare Services (NPHS) and many citizens cannot afford to purchase supplementary healthcare coverage. Furthermore, purchasing additional insurance is no guarantee that necessary care will indeed be fully covered, as these policies to limit the type and extent of coverage of services provided.

Under the US healthcare reform, citizens may choose their healthcare insurance from among a variety of existing programs. But as in Israel, the US reform does not guarantee that insurance purchased by customers will cover all necessary services and provide the entire range needed with no limitations. Many Americans may eventually end up being 
denied coverage for necessary medical care despite having purchased healthcare insurance, and just like Israelis be compelled to independently fund expensive medical treatment. Obviously, however, not everyone will be able to bear the cost, and many patients might forego medical care because they believe it is too expensive ${ }^{[2,3]}$.

Nonetheless, cost of care alone is probably not the only explanation for the decision whether to independently raise funds for medical treatment not covered by NPHS or by other types of healthcare insurance, as some patients and their families do everything they can to raise the necessary funding, while others decide to forego this option. If so, the research question is: which overall factors explain the decision whether to raise funds to care for an illness in the absence of coverage by healthcare insurances? This question is very important in light of the fact that the decision whether to raise funds is a distinct health behavior ${ }^{[4]}$, often determining patients' chances of continuing treatment, recovering, stabilizing, alleviating their suffering, extending their lives, or saving them.

Despite possible cultural and social differences between Israeli and American families, the issue of how patients and their families cope with the personal responsibility of raising funds for treatment not covered by healthcare insurance may hold relevance for US families as well.

\section{Literature review: Potential determinants of the decision whether to raise funds for treatment not included in the NPHS}

The scientific literature related to personal and family coping with illness mostly distinguishes between economic dimensions of illness, factors related to personal, spousal, and social resources of patients and their families, illness-related factors, and demographic factors, thus frustrating attempts to reach a comprehensive analysis of the entire array of issues related to this subject ${ }^{[5-7]}$.

The issue of deciding whether to raise funds for medical care not covered by the NPHS or by other types of healthcare insurance must be treated in this wide context. This is the focus of the current study, yet the lack of previous theoretical and empirical knowledge on the topic creates an objective problem concerning formulation of well-established research hypotheses. Thus, a decision was made to avoid positing research hypotheses, rather based on the previous research literature to examine the contribution of four major factors to explaining patients' decisions regarding raising funds for treatment: (1) factors related to personal, spousal, and social resources at the disposal of patients (attachment style, social support, spousal support, and spousal communication), (2) economic factors (families' financial circumstances and their transformation following the illness), (3) objective and subjective illness-related factors (such as illness onset, its course, prospective outcome, disability, level of uncertainty, symptom visibility, and patients' subjective feelings about the deleterious effect of the illness on the family's regular course of life), and (4) sociodemographic factors (such as age, gender, schooling, ethnicity, and level of religiosity). Each of the factors will be detailed below (sociodemographic factors will not be discussed in a separate section; rather they will be mentioned in each of the sections in the relevant context):

\subsection{Factors related to patients' personal, spousal, and social resources}

\subsubsection{Attachment style}

Bowlby's ${ }^{[8]}$ attachment theory was designed to explain the mechanism of attachment between an individual and his/her significant other from the moment of birth and throughout one's life. Bartholomew and Horowitz ${ }^{[9]}$ listed four attachment styles of individuals that constitute a function of their concept of self and of others: (a) the secure style characteristic of individuals with a positive self-concept and a positive concept of others; (b) the preoccupied / anxious ambivalent style, characteristic of individuals with a negative self-concept and a positive concept of others; (c) the dismissing style characteristic of individuals with a positive self-concept versus a negative concept of others; (d) the fearful style, combining a negative self-concept with a negative concept of others. 
How one copes with various aspects of illness may be explained by the individual's attachment style. There is empirical proof of the correlation between insecure attachment styles and negative health behaviors. Individuals with a dismissing attachment style are at high risk for negative health behaviors such as not appealing for help or not complying with medical treatment ${ }^{[10,11]}$.They tend to suppress their feelings and to disregard expert opinions, and thus are inclined to reinforce and preserve their distress. Patients with insecure attachment styles indicate greater difficulty trusting those in their close environment and cooperating with them on health-related issues, and accordingly, have more trouble coping with their illness and following their treatment regimen. They are inclined to report more severe levels of illness as well as a greater tendency to experience symptoms of depression. This is a result of their high sensitivity to stressful situations, their inability to ask for help and support, and the insistence of some on maintaining their independence and avoiding relying on others ${ }^{[12]}$. In light of the research findings, indicating a correlation between insecure attachment styles and negative health behaviors, it is important to examine the contribution of attachment style to the decision whether to raise funds for medical treatment not covered by the NPHS or other types of coverage.

\subsubsection{Social and spousal support in times of illness}

Social support - One's social network may serve as a significant source of support, particularly in times of stress and crisis and in situations of illness and financial strain as that characteristic of patients who need funding for medical care. The research defines social networks as systems of potential or actual ties between individuals and others whom they perceive as capable of providing them with support, sympathy, understanding, and assistance in time of need ${ }^{[13]}$.

Social support is an important part of patients' ability to adjust to their illness, cope with anxiety and stress, as well as with symptoms and manifestations of the disease ${ }^{[14]}$. Cohen et al. ${ }^{[15]}$ stressed in particular the significance of perceived support. Patients' belief that in time of need the social environment will provide them with succor contributes to enhancing their confidence and self-concept, reduces their mental distress, and improves their adjustment to illness.

Practical support may be manifested in two spheres: emotional and instrumental ${ }^{[15]}$. Emotional support is manifested in conversation and attentiveness, providing constructive feedback, encouragement, acceptance, and empathy, as well as emotional and physical availability. It gives one a sense of belonging and of being important to one's companions, and imparts a sense of self-value and belief in one's ability to cope with the disease. On the instrumental sphere, support is manifested by fulfilling the various needs that prove challenging or unmanageable for patients (such as financial aid, help with mobility and housework, setting up medical appointments, following administration of medicine, and maintaining a proper daily schedule and course of life). Among other things, the instrumental dimension includes providing patients with informative support. This may include locating and presenting information related to the disease and its care, providing advice and opinions, and even taking part in the process of reaching decisions involving the patient (such as whether to raise funds for medical care).

Spousal support - Spouses constitute one of the most important sources of support for individuals in stressful and vulnerable situations ${ }^{[16]}$. Spousal support is based on intimacy and trust, mutual commitment, positive emotional ties, and open mutual communication ${ }^{[17]}$. However, the high cost of care might constitute a threat to spouses' support of the treatment and arouse mixed feelings and tough deliberations: On the one hand, they wish to provide patients with the necessary care to alleviate their situation, stabilize their condition, and maybe even save their lives, but then again, in many cases the high cost is unaffordable. The word "cost" encompasses much more than the cost of treatment, as it includes depletion of the family's economic and mental resources, reorganization of the family's daily schedule and course of life, and changing the priorities of all family members and particularly of the caregiving spouse.

While some spousal carers embrace a protective supportive approach, others respond by displaying helplessness, anger, and detachment and experiencing burnout, desperation, and depression. As a result, their ability to provide patients with the necessary support diminishes and patients' mental and physical distress increases ${ }^{[18]}$. Adequate spousal support leads to better functioning by patients, better coping with stressful situations, and a stronger tendency to actively maintain 
behaviors that promote personal health ${ }^{[19]}$. Therefore, spousal support may have a considerable part in explaining decisions whether to raise funds for medical care not covered by the NPHS or by other types of insurance.

\subsubsection{Spousal communication}

Coping with the illness of one of the spouses depends to a large degree on the quality of spousal communication, the existence and intensity of interpersonal conflict, and spouses' joint ability to solve problems and withstand pressure ${ }^{[20]}$. Where spouses' inability to utilize interpersonal communication as a tool for efficient coping with practical and mental demands of illness might have a wide range of negative implications, positive interpersonal communication significantly contributes to reducing disparate perceptions of illness among the spouses and as a result leads to better decision making concerning medical care ${ }^{[21]}$.

Beyond the need to cope with the disease and with issues related to the routine conduct of daily life, when one spouse is ill and needs treatment not covered by the NPHS or other health insurance, spouses must cope with a wide range of financial issues. Significantly, efficient coping with difficulties, the nature of decisions made throughout the illness, and even its final outcome, might be a function of spousal ability to maintain open and adequate communication and to efficiently solve conflicts.

\subsection{Financial factors}

Many studies have examined the correlation between the illness of one family member and the family's financial situation. McCarty, Philips \& Zhong ${ }^{[22]}$ studied a sample of 1,036 colorectal cancer and lung cancer patients and found that in over $40 \%$ of families one family member was compelled to leave his/her job to care for the patient. Over $30 \%$ of patients reported losing their major source of income and $25 \%$ of patients reported spending all or some of their savings. Several years earlier, two studies conducted by Covinsky et al. ${ }^{[23,24]}$ on acute illnesses, including cancer, among samples of 3,159 and 2,129 respondents, respectively, reported that over one quarter of patients stressed at least one aspect of financial hardship as resulting from the illness, about one quarter reported the loss of their savings, and some ten percent reported having to change the family's plans and adjust to the new circumstances (for example move to a less expensive apartment and make do with family care rather than professional care) following the illness.

Slutsman, Emanuel \& Fairclogh ${ }^{[25]}$ indicated in their study that with the rise in demands posed by the disease family healthcare expenditures rise as well as patient and family carer feelings of financial hardship. They also found that $16 \%$ of respondents with an illness categorized as highly demanding were compelled to dip into their savings, sell property, or take loans or additional jobs. Tilden, Tolls \& Drach ${ }^{[5]}$ interviewed some 1,200 spouses of patients who died of cancer and asked them about expenses incurred while caring for patients. Their study indicated that $66 \%$ of respondents reported some type of financial hardship during that period and approximately $35 \%$ spent all or most their savings on caring for patients.

The studies mentioned partially explored the effect of health-related expenditures on the financial state of patients' families, but to the best of my knowledge no study has been conducted on the contribution of families' financial circumstances to decisions whether to raise funds to pay for medical care not covered by the NPHS or by other types of insurance.

\subsection{IIness-related factors}

Decisions whether to raise funds to pay for treatment should be explained not only by means of financial, personal, and social variables, but also with reference to objective and subjective illness-related variables. Rolland ${ }^{[7]}$ contended that biological aspects of illness should not be separated from its psychosocial features and offered to chart illness through a typology (the Psychosocial Typology of Illness) focusing on four dimensions significantly manifested in a variety of chronic diseases: onset of the illness, course of the illness, expected outcome of the illness, and disability. These factors can directly influence family ability to function, to maintain a normal routine, and to cope with changes, crises, and pressures. 
Furthermore, in order to better understanding all the demands and features of the illness, other parameters, such as the patient's age and role in the family upon onset, the type of treatment regimen required by the patient, symptom visibility, and whether the illness has genetic antecedents, must be taken into consideration. According to Rolland ${ }^{[7]}$, the higher the level of uncertainty regarding daily conduct throughout the illness, its process of development, aggravation, and final outcome, the more difficult it is for families to reach decisions involving both short-term and long-term planning. Moreover, the higher the uncertainty the more flexible decisions must be, and the more open to reexamination, change, or elimination.

Although Rolland's psychosocial typology manages to characterize and chart the interaction between the various demands posed by the illness and patients' and families' functioning, it almost completely neglects financial aspects of family coping with illness. Thus, two additional elements have been added here: cost and type of treatment. Cost of care requires examination of the monetary sums that patients and their families must pay for care not covered by the NPHS or other types of insurance. Type of treatment refers to the question of whether the care provided or required is life-saving, life-extending, or enhances the patient's quality of life.

\section{Research method}

\subsection{Sample}

The research population consists of patients $(n=160)$ whose essential medical care is not covered by the NPHS or other healthcare insurance, either fully or partially. Considering that some medications not covered by the NPHS are inexpensive and have no effect on the financial state of patients and their families, the research population included only patients who perceived the medical care required as costly. Of all patients, $45.6 \%$ were male and $54.4 \%$ female. All patients were married. The mean age of patients was $50.14(\mathrm{SD}=12.29)$ and the mean level of schooling was 14.83 years $(\mathrm{SD}=2.95)$.

\subsection{Research tools}

In order to examine decisions of whether to raise funds to pay for treatment, a new operational tool was developed, called the "Questionnaire on raising funds to pay for medical treatment". Patients were requested to state whether their expenditures for medication and treatments were fully or partially covered by the NPHS or by supplementary insurance. If not, they were asked to state whether they or their companions decided to continue the treatment and to raise the necessary funds. Respondents who answered in the affirmative were asked who made the decision to raise the funds. In addition, they were asked about the state of the fundraising campaign as of the date on which the questionnaire was being completed.

The following tools were used to examine the independent variables:

i. Demographic factors - A demographic questionnaire was constructed based on the Demographic and Treatment Questionnaire ${ }^{[26]}$, and it examined respondents' age, sex, ethnicity, number of children, number of years of schooling, religiosity, and length of marriage.

ii. Factors related to personal, spousal, and social resources were examined by means of the following instruments:

a. Patients' attachment style was assessed by the ECR - Experience in Close Relationships Inventory ${ }^{[27]}$. This questionnaire consists of 36 items and respondents were asked to rank on a 7-point Likert scale to what degree they agree with statements regarding their behavior and feelings in romantic relationships (lower scores indicate more secure attachment). This questionnaire is divided into two subscales examining avoidance and anxiety. In our study, reliability for the Anxiety subscale was $\alpha=0.88$ and for the Avoidance subscale $\alpha=0.88$. 
b. Perceived social support among patients - was examined through the shortened version ${ }^{[28]}$ of the Perceived Social Scale, which examines perceived social support of family caregivers ${ }^{[29]}$. Although the original questionnaire examines feelings of social support among family carers, in the current study the questionnaire was administered to the patients themselves with the aim of assessing their perceptions of social support received from family, friends, and others. Responses were given on a scale of 1-5, with higher scores indicating more positive measures of support. The questionnaire's level of reliability was determined at $\alpha=0.93$.

c. Perceived spousal support among patients was assessed by means of the Interpersonal Relationship Inventory (IPRI) ${ }^{[30]}$. This questionnaire is composed of three subscales: social support (referring to support provided by the spouse), reciprocity, and conflict. Responses were given on a scale ranging from 1-5, with higher scores indicating more positive measures of support, higher reciprocity, and lower conflict. Alpha values were $\alpha=0.95$ for the entire questionnaire, $\alpha=0.82$ for the Social Support subscale, $\alpha=0.87$ for the Reciprocity subscale, and $\alpha=0.81$ for the Conflict subscale.

d. Spousal communication was assessed by means of two subscales from the 115-item ENRICH inventory ${ }^{[31]}$ : The Communication and Conflict Resolution Subscales. Responses were on a scale of 1 to 5 , with a higher score indicating more positive measures of communication. In the current study, reliability for the entire questionnaire was $\alpha=0.84$, for the Communications subscale $\alpha=0.8$, and for the Conflict subscale $\alpha=0.77$.

iii. Financial factors - This questionnaire was constructed specifically for the current study. Patients were requested to state their subjective evaluation of their family's socioeconomic status before the illness and following its emergence (on a scale of 1-5, 1=low, 5=high), their income range (from salary and other sources), and their monthly expenditures before the illness and following its emergence.

iv. Objective and subjective illness-related factors - This questionnaire was constructed based on the Psychosocial Typology of Illness ${ }^{[7]}$ (Rolland, 1994) and it refers to the following components: illness onset, course, expected outcome, disability, level of uncertainty (regarding daily conduct during the illness, its process of development, aggravation, and final outcome), symptom visibility, patients' perception of the deleterious effect of the illness on the family's regular course of life, genetic antecedents of the illness, treatment regimen, and the patient's role in the family at onset. In addition, issues regarding the cost of prescribed care were presented, as well as whether treatment is live-saving, life-extending, or life-enhancing. Patients were also asked to subjectively rank the severity of their illness on a scale of 1 to $10(1=$ very severe, $10=$ not at all severe) (Clinical Global Impressions Survey - Severity Scale) ${ }^{[32]}$. All questions in this questionnaire have a different range of responses according to the relevant context and some are open-ended, therefore no reliability test was conducted for internal consistency of the entire questionnaire.

\subsection{Procedure}

The current research population has unique attributes and no public sources of information are available to determine its characteristics and size; thus, random sampling methods were not feasible. As a result, snowball sampling was employed: Patients whom we had met in the process of the study were approached and asked to connect us to other patients whom they had met while at hospitals, clinics, or support groups. Some of the respondents were identified in hospital wards and at medical institutes, however all questionnaires were completed at their homes. When completed, the questionnaires were sealed in opaque envelopes and given to the researcher. 


\section{Findings}

The study examined the contribution of factors related to personal, spousal, and social resources at patients' disposal, economic factors, illness-related factors, and sociodemographic factors, to the decision whether to raise funds for medical treatment of one of the spouses. I shall begin by presenting the distribution of variables related to fundraising and then continue with findings on each of the factors mentioned above.

\subsection{Raising funds for medical care}

Most of the patients (55.3\%) reported that they and their spouses decided together whether to raise funds to pay for treatment. The proportion of patients who reached the decision alone was $17.1 \%$ and $8.1 \%$ stated that their spouse made the decision for them. In the remaining cases patients reported the involvement of friends, parents, and the extended family.

At the time the questionnaire was completed, only $25.9 \%(n=37)$ of respondents reported that they had managed to raise the necessary funds and were continuing to receive the required treatment. The proportion of respondents who reported that they had not managed to raise funding for the care needed and were currently receiving an alternate less desirable treatment was $14.7 \%(\mathrm{n}=21)$. The proportion of respondents who had tried to raise the money but did not succeed and thus did not receive any medical treatment was $2.1 \%(n=3)$, while $6.3 \%$ of respondents $(n=9)$ reported that they had had variable success in raising the funds and therefore their treatment was inconsistent, and $34.3 \%(\mathrm{n}=49)$ completely forego any attempts to raise funds. Regarding the decision whether to continue treatment, $73.1 \%(\mathrm{n}=117)$ of the 151 respondents decided to continue treatment, while $21.3 \%(n=34)$ made a decision not to continue. Notably, of the 49 respondents who forego all attempts to raise funds to pay for treatment, 31 discontinued their treatment.

\subsection{Factors related to patients' personal, spousal, and social resources}

In some of the factors related to personal, spousal, and social resources, significant differences were found between those who decided to raise funds for medical care and those who decided not to do so. Patients who decided not to raise finds received higher scores on the avoidant attachment scale than those who decided not to forego fundraising $(t=1.94, p<0.05)$. Patients who decided to raise funds had a more positive perception of their social support $(t=-1.99, p<0.05)$, indicated higher spousal support $(t=-2.31, p<0.05)$, a higher degree of reciprocity between themselves and their spouses $(t=-2.73$, $p<0.01)$, and better spousal communications $(t=-2.43, p<0.05)$ than those who decided not to raise funds.

\subsection{Economic factors}

\subsubsection{I ncome}

The current study showed that illness onset was followed by a significant drop in family income. The proportion of patients who reported a family income of less than NIS 8,000 before the illness remained unchanged in its aftermath, at about 30\%. Before the illness most patients (44.2\%) reported a family income of over NIS 15,000 a month, but following the illness this percentage dropped to $34.4 \%$. The proportion of patients who reported a family income of NIS $8,000-15,000$ following the illness rose to $35.8 \%$, versus $26.2 \%$ before the illness.

\subsubsection{Expenditures}

Several patients reported a rise in their family's expenditures following the illness. While before the illness $38.5 \%$ of patients reported monthly expenditures of less than NIS 7,000, following the illness this proportion dropped to $29.1 \%$ of patients. The proportion of respondents who reported expenditures of NIS 7,000-13,000 rose from $28 \%$ to $33.4 \%$. In addition, there was a rise in reported family expenditures of over NIS 13,000 , from $33.5 \%$ to $37.5 \%$. 


\subsubsection{I mpact of economic factors on the decision whether to raise funds}

A comparison between those who raised funds and those who decided not to raise them, as measured by economic criteria, showed only a limited number of significant findings; patients who decided not to raise funds for treatment reported a lower drop in the family's socioeconomic status $(t=-2.94, p<0.01)$ and a lower difference in pay following the illness $(t=-2.4, p<0.05)$ than patients who decided to raise funds. However no significant differences were found in disparities between family income $(t=-.13, p>0.05)$ and family expenditures $(t=-0.23, p>0.05)$ before and following illness onset.

\subsection{IIness-related factors}

\subsubsection{IIness-related factors (Rolland, 1994) [7]}

Significant differences were found between patients who decided to raise funds for treatment and those who decided not to, in their perceived uncertainty in regard to the course of the illness $(\mathrm{M}=4.5, \mathrm{SD}=3$ among fundraisers versus $\mathrm{M}=5.65$, $\mathrm{SD}=3.35$ among non-fundraisers, $t=2.08, p<0.05)$ and its final outcome $(\mathrm{M}=3.91, \mathrm{SD}=2.81$ among fundraisers versus $\mathrm{M}=5.14, \mathrm{SD}=3.04$ among non-fundraisers, $t=2.33, p<0.05)$, as well as in regard to the feeling that their illness has a deleterious effect on their family's normal course of life $(\mathrm{M}=3.09, \mathrm{SD}=1.17$ among fundraisers versus $\mathrm{M}=2.62, \mathrm{SD}=1.31$ among non-fundraisers, $t=-2.177, p<0.05)$. No significant differences were found in all other illness-related parameters.

\subsubsection{The cost of medical care}

The average monthly expenditure on medication not included in the NPHS was NIS 2,248.86 (SD=4,452). No significant difference was found in the cost of treatment between those who decided to raise funds for treatment $(\mathrm{M}=2463.2$, $\mathrm{SD}=5102.19$, monthly mean in shekels) and those who decided not to $(\mathrm{M}=1497.95, \mathrm{SD}=2118.38$, monthly mean in shekels) $(t=-1.204, p>0.05)$.

\subsubsection{Type of care needed}

Of the 160 patients in the study, 130 answered the question on the type of care they need. Of those who responded, 33.1\% $(n=43)$ stated that they need life-saving treatment, $21.5 \%(n=28)$ stated that they need life-extending treatment, and $45.4 \%$ $(n=59)$ stated that they need treatment that would enhance their quality of life. Although no dependence was found between the type of care needed and the decision whether to raise funds for it $\left(\chi^{2}=1.19, p>0.05\right)$, the findings show that a fairly high proportion of patients decided not to raise funds to pay for treatment. This percentage was higher among patients who needed life-extending treatment (42.9\%) than among patients who needed life-saving treatment (36.8\%) and patients who needed treatment that would enhance their quality of life $(30.8 \%)$.

\subsection{Demographic factors}

Examination of demographic differences between patients who decided to raise funds for treatment and those who decided not to, found no significant differences. For example, the mean age of fundraisers was $50.62(\mathrm{SD}=11.7)$ and of non-fundraisers $49.54(\mathrm{SD}=13.3)(t=-0.5, p>0.05)$, the mean level of schooling of fundraisers was 14.8 years $(\mathrm{SD}=3)$ and of non-fundraisers 14.7 ( $\mathrm{SD}=1.93)(t=-0.18, p>0.05)$. In addition, no dependence was found between patients' gender, ethnicity, and religiosity, and between the decision whether to raise funds $\left(\chi^{2}=0.001, p>0.05, \chi 2=0.958, p>0.05, \chi^{2}=0.008\right.$, $p>0.05$, respectively).

\subsection{Model predicting the decision whether to raise funds for medical care not covered by the NPHS and other health insurance}

In order to examine the joint contribution of factors related to personal, spousal, and social resources and demographic, economic, and illness-related factors to the decision whether to raise funds for medical care, a logistic regression was performed (see Table 1). This regression serves to predict the results of one binary dependent variable based on one or more predictors through a linear function, with the purpose of assessing the odds ratio that a certain event will occur. The value of $\operatorname{Exp}(\mathrm{B})$ indicates a rise in the odds ratio of the occurrence of the explained event when an independent variable 
rises by one unit ${ }^{[33]}$. This generated a model predicting the odds ratio of raising funds for medical care. Some of the main variables were not included in this model due to the high multicollinearity with some of the variables included.

Table 1. Logistic regression model predicting the decision whether to raise funds for medical care

\begin{tabular}{|c|c|c|c|c|c|c|}
\hline \multirow{2}{*}{ Research variables } & \multirow{2}{*}{$\operatorname{Exp}(B)$} & \multirow{2}{*}{ Wald $(\mathbf{d f}=1)$} & \multirow{2}{*}{ S.E. } & \multirow{2}{*}{ B } & \multicolumn{2}{|c|}{ 95\% C.I. for EXP(B) } \\
\hline & & & & & Lower & Upper \\
\hline Age at marriage & .78 & $7.374 * *$ & .091 & -.248 & .653 & .933 \\
\hline $\begin{array}{l}\text { Drop perceived by patients in their family's socioeconomic } \\
\text { status }\end{array}$ & 5.68 & $13.654 * * *$ & .470 & 1.737 & 2.261 & 14.275 \\
\hline Change (for the worse) in patients' pay following the illness & 1.65 & $8.131 * *$ & .176 & .502 & 1.170 & 2.331 \\
\hline Spousal communication & 4.63 & $5.913 *$ & 630 & 1.533 & 1.346 & 15.929 \\
\hline Anxiety & 2.42 & $6.458^{*}$ & .347 & .882 & 1.223 & 4.766 \\
\hline Social support & 1.73 & $1.696^{*}$ & .420 & .547 & .759 & 3.933 \\
\hline Uncertainty following the illness & .74 & $4.192 *$ & .144 & -.295 & .561 & .987 \\
\hline $\begin{array}{l}\text { Deleterious effect of the illness on the family's regular course } \\
\text { of life }\end{array}$ & .55 & $3.979 *$ & .301 & -.600 & .305 & .990 \\
\hline
\end{tabular}

Constant $=-1.63 ;-2$ Log Likelihood $=89.48$, Nagelkerke R Square $=0.525$, Cox \& Snell R Square $=0.378, \chi^{2}(8)=53.43 p<0.001$

${ }^{*} P<0.05$

${ }^{* * *} P<0.01$

${ }^{* * * *} P<0.001$

In regards to sociodemographic factors, age at marriage was found to significantly explain the odds of raising funds for medical care. The higher patients' age of marriage to their current spouse, the lower their odds of raising funds (each added year in age at marriage reduces the odds of raising funds by a factor of $0.78, p<0.01$ ). In regards to economic factors, the more patients felt that there had been a significant drop in the family's socioeconomic status following the illness, their odds of raising funds rose by a factor of $5.68(p<0.001)$. The more significant the drop in patients' income following the illness, their odds of raising funds rose by a factor of $1.65(p<0.01)$. Regarding factors related to one's social, spousal, and personal features, better spousal communications, social support, and an anxious attachment style were found to increase the odds of raising funds by a factor of $4.63(p<0.05), 1.73(p<0.05)$, and $2.42(p<0.05)$, respectively. In regard to illness-related factors, the higher the level of uncertainty accompanying the illness (this measure is composed of the average of four questions on uncertainty regarding daily life during the illness, its course of development, aggravation, and final outcomes), the lower the odds of raising funds by a factor of $0.74(p<0.05)$. Moreover, when patients felt that their illness has a deleterious effect on their family's regular course of life, these odds decreased by a factor of $0.55(p<0.05)$. Examination of the full model versus the model with the constant only ${ }^{[33]}$ produced significant results $\left(\chi^{2}(8)=53.43\right.$, $p<0.001$ ), showing that the predictors in the model significantly distinguish between those who decide to raise funds and those who decide to forego raising funds for medical care. Nagelkerke $R^{2}(0.525)$ indicated fairly good compatibility between the predictors and the dependent variable.

\section{Discussion}

Financial difficulties require patients and their families to reach complex decisions concerning treatment and raising funds for medical care. Similar to the findings of previous studies ${ }^{[22]}$, most of the patients in the current study reported a drop in the family's income and a rise in expenditures following the illness. In some cases, following the illness patients, as well as spouses, are forced to reduce their work load or to leave their job completely, while financial expenses pile up (for example costs of medication, treatments, medical instrumentation, transportation, etc.). Raising funds for medical care may be not only a means of saving or improving the patient's condition, rather a means of reviving the patient as a functioning individual, one who helps support the family and is sometimes the only or primary breadwinner ${ }^{[7]}$, or a means of ensuring that the family's existing financial resources are not harmed, thus facilitating its financial existence and functioning. 
The model for predicting the odds ratio of raising funds for medical care shows that some of the factors related to perceived social and personal resources available to the patient have a significant effect on the decision whether to raise funds. A supportive atmosphere contributes to adjustment and to better patient handling of their condition, as well as to reducing the effect of the stress experienced, with the effect of implementing more positive health behaviors ${ }^{[34]}$. Consistently, the current study reveals that social support was related to more positive health behaviors, specifically the decision to raise funds to pay for medical care.

Similar to other studies ${ }^{[35,36]}$ which indicated that communication style between spouses affects their ability to solve problems and largely determines the nature of the decisions they make, good spousal communication was found to increase the odds of reaching a decision in favor of raising funds to pay for medical care. An anxious attachment style was also found to contribute to the decision to raise funds for medical care. This may be explained by the tendency of people with this attachment style to adopt active patterns of action to cope with illness. These patterns include seeking support, approaching advisors and experts, frequent visits to clinics, and seeking detailed information about the illness ${ }^{[37,38]}$. The decision to act to raise funds may be assumed to be one of the actions taken by people with this attachment style in order to reduce the level of anxiety and risk that accompany the illness. Significantly, although anxious attachment style was found to contribute to the decision to raise funds for medical care, this does not necessarily indicate that those patients eventually manage to raise the funds and consistently adhere to all treatment requirements.

Due to the higher multicollinearity, some of the variables related to spousal relations and personal and social resources were not included in the model predicting the decision whether to raise funds; however significant differences were found between those who decided to raise funds and those who decided not to in major variables such as avoidant attachment and spousal support. In regard to patients' attachment style, studies indicate that people with an avoidant attachment style display very problematic health behaviors, such as the inclination to embrace a fatalist approach or to deny their medical condition ${ }^{[10,39]}$. Similar to these studies, the current study as well showed that patients who decided not to raise funds scored higher on avoidant attachment style than patients who decided to raise funds. Spousal support is another variable for which differences were found between those who decided to raise funds and those who decided not to; patients who chose to raise funds for medical care had a more positive evaluation of their spousal support. This finding corroborates previous findings showing that spousal support has a significant effect on evolvement of the illness, its manner of treatment, and final consequences, as well as on the quality and course of decision making within the family ${ }^{[6,40]}$. Reciprocity, constituting one of the most important basic components of spousal support, is essential for regular functioning of a normal relationship ${ }^{[30]}$. Exchange theory states that individuals in a giving and receiving relationship expect to receive a reward of at least equal worth (subjectively) to that given. Indeed, the current study found that patients who reached a decision to raise funds for medical care had a more positive appreciation of the reciprocity in their spousal relationship.

Sociodemographic variables are conspicuous for their lack of effect on the decision whether to raise funds. None of the variables, excluding age at marriage, had any significant effect. Marrying at a very young age is perceived in western society as putting one at high risk for a weak marriage and for divorce ${ }^{[41]}$. However the research shows that the connection between age at marriage and stability of marital life is not linear ${ }^{[42]}$ and that beginning from the late $20 \mathrm{~s}$, the situation is reversed, creating a negative relationship between age at marriage and stability of marital life. This finding might explain the lower tendency to raise funds for medical care among patients who married at an older age, since as stated, a supportive spousal relationship is often an important condition for positive spousal and personal coping with illness.

While no correlation was found between the type of care and its cost and between the decisions whether to raise funds, factors related to patients' subjective view of their illness were found to have a significant effect on this variable. McDaniel, Hepworth \& Doherty ${ }^{[42]}$ stated that many patients might feel that their illness is a mental, emotional, physical, and financial burden on the entire family and particularly on their spouses. The current study found that patients who felt that the illness has a deleterious effect on their family's regular course of life had lower odds of raising funds for medical 
care. Raising funds requires the family to invest many mental resources, motivation, time, logistic arrangements, etc. Patients who felt that their illness had taken too high a toll on their family and had a deleterious effect on its regular course of life may not have been ready to exact an additional price from their family by using existing resources to raise funds for medical care. Moreover, families in a daily situation of functional difficulty due to the illness of one of the spouses might be in too deep a crisis to function in the instrumental, organized, and efficient manner necessary in order to raise funds for the patient.

Another factor that reduces the odds of raising funds is a larger sense of uncertainty following the illness. According to Rolland ${ }^{[7]}$ high uncertainty regarding daily conduct during the illness, its process of development, aggravation, and its expected outcome makes it difficult to reach decisions and has a detrimental effect on the ability to plan in advance. In contrast, families who manage to gather information about the illness and its treatment, who are capable of managing a flexible role division between their members, and who utilize instrumental and mental resources in their social environment, are better able to cope with strong crises and with uncertainty.

\section{Research limitations}

One of the significant limitations of this study was the objective difficulty of randomly sampling a representative sample of patients requiring medical care not funded by healthcare insurance. Although the study included respondents from all areas of Israel, no minorities were sampled due to the non-random sampling method. The sample was less representative also due to its limited size. In Israel there is no official recording of the researched population and therefore it was very difficult to obtain a sample of patients who not only had to fund medical care independently, but also felt that this expense is a financial burden. Furthermore, it was important to reach respondents at such a stage of their illness when they could fully respond to the questionnaire, both physically and mentally. In the future, it would certainly be desirable to repeat the study and examine its findings among a larger sample.

The spousal perspective utilized by the current study seems to have proven itself. Many decisions related to raising funds for medical care were found to be a function of the spousal dynamics. However in order to reach a thorough understanding of the subject it is important to interview the spouses and other family members as well.

\section{Research conclusions and recommendations for social and health security policies}

When patients and their families are exposed to a situation in which they must cope with illness, with its personal, spousal, and social implications, as well as with financial strains, they might also encounter some complicated dilemmas concerning continued care and raising funds for this purpose. This fact has far reaching implications for policy planning, professional intervention, and for working with these families. Thorough knowledge of factors that promote or prevent decisions on raising funds for medical care will help facilitate the construction of support and aid programs that assist patients and their families from the psychological, interpersonal, social, and informative perspective.

Israel currently has no well-defined policy on this issue, it is not clear who is responsible for it and in what framework. In addition, there are no experts who specialize specifically in the wide range of problems that these families might encounter. The existence of institutionalized support mechanisms, including interdisciplinary teams that can provide support and advice, is essential in this case. It is also important that professional elements realize that the concept of patients who avoid raising funds for medical care only due to the high cost involved might be misleading. As stated, this issue is also related to a wide variety of considerations related to other personal, social, demographic, economic, and health related factors. Professionals must also act to increase the awareness of patients and their spouses of the implications of the spousal dynamics for decision making and provide them with constant support and advice on this subject. 
Following the US healthcare reform, decision makers and policy planners in the US healthcare system might also encounter some of the issues described in this article. It may be advisable to learn from the experience of other countries, including Israel, in order to thoroughly consider and plan a well thought out and efficient policy that can best provide for the healthcare needs of all citizens.

\section{References}

[1] State of Israel. National Health Insurance Law, (1994). (Hebrew)

[2] Dgani A, Dgani R. Consumption of health care services in Israel [Internet]. Center versus periphery. Geocartography Institute. 2008. Available from: www.ima.org.il. (Hebrew)

[3] Israeli Medical Association [Internet]. 2009. Available from: http://www.ima.org.il/MainSite/ViewCategory. aspx?CategoryId=1803

[4] Gochman, D. S., (Ed.). Handbook of Health Behavior Research. New York: Plenum. 1997.

[5] Tilden, V.P., Tolle, S.W. \& Drach, L.L. Out-of-hospital death: advance care planning, decedent symptoms, and caregiver burden. Journal of American Geriatric Society. 2004; 52: 532-9. PMid:15066067 http://dx.doi.org/10.1111/j.1532-5415.2004.52158.x

[6] Padula, C. \& Sullivan, M. Long-term married couples: health promotion behaviors. Journal of Gerontological Nursing. 2006.

[7] Rolland, J. S. Families, illness \& disability. NY: Basic Books. 1994. PMid:17048755

[8] Bowlby, J. Attachment and loss: Vol. 1. Attachment. New York: Basic Books. 1969.

[9] Bartholomew, K. \& Horowitz, L.M. Attachment styles among young adults: A test of a four category model. Journal of Personality and Social Psychology. 1991; 61: 226-224. PMid:1920064 http://dx.doi.org/10.1037/0022-3514.61.2.226

[10] Kotler, T., Buzwell, S., Romeo, Y. \& Bowland, J. Avoidant attachment as a risk factor for health. British Journal of Medical Psychology. 1994; 67(3): 237-245. PMid:7803316 http://dx.doi.org/10.1111/j.2044-8341.1994.tb01793.x

[11] Ciechanowski, P. S., Katon, W. J., Russo, J. E \& Walker, E. A. The patient-provider relationship: Attachment theory and adherence to treatment in diabetes. The American Journal of Psychiatry. 2001; 158(1): 29-35. PMid:11136630 http://dx.doi.org/10.1176/appi.ajp.158.1.29

[12] Meredith, P. J., Strong, J., \& Feeney, J. A. Adult attachment variables predict depression before and after treatment for chronic pain. European Journal of Pain. 2007; 11: 164-170. PMid:16517191 http://dx.doi.org/10.1016/j.ejpain.2006.01.004

[13] Milardo, R. M. Families and social networks: An overview of research and methodology. In R. M. Milardo (Ed.), Families and social networks (pp. 13-47). Thousand Oaks, CA: Sage Publications. 1988.

[14] Pernice-Duca, F. Family network support and mental health recovery. Journal of Marital and Family Therapy. 2010; 36(1): 13-27. PMid:20074121 http://dx.doi.org/10.1111/j.1752-0606.2009.00182.x

[15] Cohen, S., Gottlieb, B. H., \& Underwood, L. G. Social relationships and health. In S. Cohen, L. G. Underwood, \& B. H. Underwood (Eds.), Social support measurement and intervention: A guide for health and social scientists, (pp. 3-25). New York: Academic Press. 2000. PMid:10788554

[16] Hinnen, C., Hagedoorn, M., Sanderman, R., \& Ranchor, A. The role of distress, neuroticism and time since diagnosis in explaining support behaviors in partners of women with breast cancer: results of a longitudinal analysis. Psycho - Oncology. 2007; 16(10): 913. PMid:17265542 http://dx.doi.org/10.1002/pon.1153

[17] Kane, C.F. Family social support: Toward a conceptual model. Advances in Nursing Science. 1988; 10(2): 18-25. PMid:3124718

[18] Thoits, R. A. Stress, coping, and social support processes: Where are we? What next? Journal of Health and Social Behavior (Extra Issue). 1995; 53-79. PMid:7560850 http://dx.doi.org/10.2307/2626957

[19] Bodenmann, G. Dyadic coping and its significance for marital functioning. In T. Revenson, K. Kayser, \& G. Bodenmann (Eds.). Emerging perspectives on couples coping with stress. Washington, DC: American Psychological Association. 2005. PMid:15965828 http://dx.doi.org/10.1037/11031-002

[20] Bodenmann, G., Pihet, S., \& Kayser, K. The relationship between dyadic coping and marital quality: A 2-year longitudinal study. Journal of Family Psychology. 2006; 20(3): 485-493. PMid:16938007 http://dx.doi.org/10.1037/0893-3200.20.3.485

[21] Soloway, C., Soloway, M., Kim, S., \& Kava, B. Sexual, psychological and dyadic qualities of the prostate cancer couple. British Journal of Urology. 2005; 95(6): 780-785. PMid:15794782 http://dx.doi.org/10.1111/j.1464-410X.2005.05400.x

[22] McCarthy, E. P., Phillips, R. S. \& Zhong, Z. Dying with cancer: patients' function, symptoms, and care preferences as death approaches. Journal of American Geriatric Society. 2009; 48: 110-121.

[23] Covinsky, K. E., Goldman, L. \& Cook, E.F. The impact of serious illness on patients' families. Support Investigators. Study to Understand Prognoses and Preferences for Outcomes and Risks of Treatment. 1994; 272: 1839-44. 
[24] Covinsky, K.E, Landefeld, C.S. \& Teno, J. Is economic hardship on the families of the seriously ill associated with patient and surrogate care preferences? Support Investigators. 1996; 156: 1737-41.

[25] Slutsman, J., Emanuel, L.L, \& Fairclough, D. Managing end-of-life care: comparing the experiences of terminally ill patients in managed care and fee for service. Journal of American Geriatric Society. 2002; 50: 2077-83. http://dx.doi.org/10.1046/j.1532-5415.2002.50622.x

[26] Franze, S. Perfectionism as a mediator between parent-child interactions and attachment style in adult romantic relationships. A Phd Thesis in Counseling Psychology. The Pennsylvania State University. 2005.

[27] Brennan, K. A., Clark, C.L., \& Shaver, P. R. Self- report measurement of adult attachment: An integrative overview. In J. A. Simpson \& W.S. Rholes (Eds.). Attachment, Theory and Close Relationships. 1998; 46-76. New York, NY: The Guilford Press. PMid:11567402

[28] Wen Juian, Y. Meaning of caregiving, perceived social support and level of depression of Taiwanese caregivers of mentally ill patients and their service needs in the community. The University of Wisconsin-Milwaukee. 2003.

[29] Blumenthal, J. A., Barefoot, J. \& Haney, T. Social support, type A behavior, and coronary artery disease. Psychosomatic Medicine. 1987; 49: 331-340. PMid:3615762

[30] Tilden, V. P. (1993). Interpersonal relationship inventory. Unpublished manuscript, Oregon Health Sciences University at Portland. In Sabone, M. B. (2002). The relationship of illness and marital support to psychological adjustment to chronic illness among middle-aged Batswana couples. Frances Payne Bolton School of Nursing, Case Western Reserve University.

[31] Olson, H. D., Fournier G. D., \& Druckman, M. J. ENRICH- Enriching \& Nurturing Relationship Issues, Communication \& Happiness. In H. D. Olson, H.I .Mccubin, H. Barnes, A. Larsen, M. Muxen \& M. Wilson (Eds.). Family inventories. University of Minnesota: Family Social Science. 1982.

[32] Guy, W. ACDEU Assessment Manual for Psychopharmacology. US Dept Health, Education and Welfare publication (ADM) 76-338. Rockvile, Md: National Institute of Mental Health. 1976; 218-222.

[33] Field, A. Discovering statistics using SPSS. New York: Sage. 2005.

[34] Laireiter, A., \& Baumann, U. Network structures and support functions: Theoretical and empirical analyses. In H. O. F. Veiel, \& U. Baumann (Eds.), the meaning and measurement of social support (pp. 33-55). Washington, DC: Hemisphere Publishing Corp. 1992.

[35] Vuchinich, S. Starting and stopping family conflicts. Journal of Marriage and Family. 1987; 49: 591-609. http://dx.doi.org/10.2307/352204

[36] Cutrona, C. E. Social Support in Couples. Thousand Oaks, CA: Sage. 1996.

[37] Feeney, J. A., \& Ryan, S. M. Attachment style and affect regulation: Relationships with health behavior and family experiences of illness in a student sample. Health Psychology. 1994; 13(4): 334-345. PMid:7957012 http://dx.doi.org/10.1037/0278-6133.13.4.334

[38] Stuart, S., \& Noyes, R. Attachment and interpersonal communication in somatization. Psychosomatics. 1999; 40(1): $34-43$. http://dx.doi.org/10.1016/S0033-3182(99)71269-7

[39] Feeney, J.A. Attachment style, com $\neg$ munication patterns and satisfaction across the life cycle of marriage. Personal Relationships. 1994; 1: 333-348. http://dx.doi.org/10.1111/j.1475-6811.1994.tb00069.x

[40] Lichtman, R. R., Taylor, S. E. \& Wood, J. V. Social support and marital adjustment after breast cancer. Journal of Psychosocial Oncology. 1987; 5: 47-74. http://dx.doi.org/10.1300/J077v05n03_03

[41] Teachman, J. Stability across Cohorts in Divorce Risk Factors. Demography. 2002; 39: 331-351. http://dx.doi.org/10.1353/dem.2002.0019

[42] Lehrer, E. L. Age at marriage and marital instability: Revisiting the Becker-Landes-Michael hypothesis. Journal of Population Economics. 2008; 21(2): 463-484. http://dx.doi.org/10.1007/s00148-006-0092-9 